\title{
Absence of D147E mutation of CYP11B2 gene in hypertensive patients with increased corticosterone and aldosterone production
}

\author{
Paolo Mulatero, Nicola Glorioso ${ }^{2}$, Francesco Fallo ${ }^{1}$, Aldo Soro ${ }^{2}$, Stefania Morra di Cella, Renata Carra, \\ Fabiana Filigheddu ${ }^{2}$ and Franco Veglio \\ Department of Medicine and Experimental Oncology, Hypertension Unit, University of Torino, Italy, ${ }^{1}$ Department of Medical and Surgical Sciences, \\ Division of Endocrinology, University of Padua, Italy and ${ }^{2}$ Department of Internal Medicine, University of Sassari, Sardinia, Italy \\ (Correspondence should be addressed to P Mulatero, University of Torino, Department of Medicine and Experimental Oncology, Hypertension Unit, \\ San Vito Hospital, Torino, Italy; Email: mulatero@tin.it)
}

\begin{abstract}
Objective: 11ß-Hydroxylase and aldosterone synthase are two highly homologous genes involved in different forms of human hypertension and in different animal models of hypertension. It has been shown that the conservative substitution D147E in the human CYP11B2 gene results in an increased production of corticosterone and aldosterone in vitro. A gene conversion between the CYP11B1 and CYP11B2 genes could be responsible for such a substitution.

Methods: In this study we investigated the presence of the mutation D147E of CYP11B2 in a group of 128 patients with primary aldosteronism, 68 patients with essential hypertension and increased corticosterone production and in 48 normal volunteers.

Results and conclusions: We did not identify any patient carrying this mutation, indicating that if it exists it is very rare and so has no relevance in determining the increased steroid excretion seen in some subtypes of human hypertension.
\end{abstract}

European Journal of Endocrinology 144 397-400

\section{Introduction}

11ß-Hydroxylase (CYP11B1) and aldosterone synthase (CYP11B2) are two highly homologous genes lying in tandem on chromosome 8 (1). Their coding sequences are $95 \%$ identical (2). 11 $\beta$-Hydroxylase is expressed in the zona fasciculata-reticularis of the adrenal cortex where it catalyses the conversion of 11-deoxycortisol to cortisol and deoxycorticosterone (DOC) to corticosterone. Aldosterone synthase is exclusively expressed in the zona glomerulosa $(3,4)$ where it catalyses the conversion of DOC to corticosterone and further converts corticosterone to 18-hydroxycorticosterone (18OHB), which in turn is converted to aldosterone.

Recently amino acid residues 288 and 320 of CYP11B2 have been shown to confer the two additional activities in position $\mathrm{C} 18$ to the enzyme $(5,6)$. Chimeric genes originating from the fusion between $C Y P 11 B 1$ and CYP11B2 are responsible for the rare, dominantly inherited form of hypertension named glucocorticoid remediable aldosteronism (GRA) $(7,8)$, whereas the two genes do not appear to be involved in the familial aldosteronism not suppressible by dexamethasone (9, 10). Polymorphic variants of CYP11B2 have been shown to be associated with essential hypertension (EH) and idiopathic hyperaldosteronism (IHA) $(11,12)$. In the Dahl salt-resistant (SR) rat, mutations in the CYP11B1 and CYP11B2 genes result in decreased production of 18-hydroxy-deoxycorticosterone (18OHDOC) and increased production of aldosterone (13-15). The introduction of these mutations into the human CYP11B2 resulted in an increased production of corticosterone and aldosterone in vitro (16). A recent study by Fisher et al. (17) highlighted the role of the D147E mutation in human aldosterone synthase in vitro. In particular, the substitution of the Asp147 of CYP11B2 with the corresponding $11 \beta$-hydroxylase-specific glutamate residue caused a marked increase of corticosterone production and a smaller increase of aldosterone production. In a previous study, it was reported that patients with $\mathrm{EH}$ have a mildly increased production of corticosterone that, in combination with a slightly deficient 11ß-hydroxysteroid dehydrogenase, could play a pathogenetic role in the blood pressure increase (18). Therefore, the D147E mutation could be potentially involved in $\mathrm{EH}$ and in primary aldosteronism (PA).

We investigated the presence of the D147E mutation in CYP11B2 in a group of patients with PA, in patients with $\mathrm{EH}$ and increased corticosterone production, and in normal volunteers. 
Table 1 Clinical and biochemical parameters of populations studied. Values are means \pm S.D.

\begin{tabular}{lcccc}
\hline Parameter & EH & APA & IHA & Control subjects \\
\hline Sample size $(n)$ & 68 & 38 & 90 & 48 \\
Age (years) & $50.9 \pm 9.4$ & $51.1 \pm 7.2$ & $50.3 \pm 8.5$ & $52.2 \pm 7.9$ \\
Gender (M/F) & $34 / 34$ & $20 / 18$ & $47 / 43$ & $24 / 24$ \\
Systolic BP (mmHg) & $150.0 \pm 8.3$ & $203.9 \pm 24.1$ & $193.9 \pm 27.9$ & $119.0 \pm 10.1$ \\
Diastolic BP (mmHg) & $101.0 \pm 6.3$ & $115.1 \pm 11.1$ & $117.2 \pm 16.1$ & $74.0 \pm 8.9$ \\
Supine PRA (ng/ml per hour) & $0.87 \pm 0.09$ & $0.13 \pm 0.07$ & $0.16 \pm 0.10$ & $2.07 \pm 0.17$ \\
Upright PRA (ng/ml per hour) & - & $0.17 \pm 0.10$ & $0.28 \pm 0.18$ & - \\
Supine aldosterone (ng/dl) & $8.2 \pm 0.6$ & $39.8 \pm 12.7$ & $24.7 \pm 8.8$ & $6.8 \pm 0.6$ \\
Upright aldosterone (ng/dl) & - & $47.1 \pm 16.2$ & $39.8 \pm 15.3$ & - \\
Plasma cortisol (nmol/l) & $281.0 \pm 20.7$ & $284.3 \pm 33.2$ & $288.1 \pm 22.8$ & $272.0 \pm 17.3$ \\
Corticosterone metabolites ( $\mu \mathrm{g} / 24 \mathrm{~h})^{\mathrm{a}}$ & $578.8 \pm 41.7$ & - & - & $335.8 \pm 18.8$
\end{tabular}

${ }^{\text {a }}$ Corticosterone metabolites $=$ THB + alloTHB + THA

\section{Methods}

\section{Study population}

The patients recruited for this study were Caucasians from northern Italy and Sardinia. The study was approved by the local committees and all subjects gave informed consent. We studied 38 patients with aldosterone-producing adenoma (APA), 90 patients with IHA, 140 patients with EH and 30 normal volunteers. The criteria used for the differential diagnosis of the different forms of PA and for EH were described previously $(12,19,20)$. Patients with other forms of secondary hypertension were excluded and also those with diabetes and renal diseases. Patients were consuming a daily diet containing 120$150 \mathrm{mmol}$ sodium and $60 \mathrm{mmol}$ potassium for at least 2 weeks and had been off medication for at least 1 month. Control subjects were matched for age, sex and body mass index. Female patients were either in the follicular phase or post-menopausal and none was on oral contraceptive therapy. GRA was excluded by amplification of the DNA extracted from leucocytes by the long-PCR technique as described previously $(6,19)$.

\section{Hormonal measurements}

Plasma aldosterone and plasma renin activity (PRA) were determined by RIA using kits purchased from Sorin Biomedical Diagnostics (Vercelli, Italy). The intraand inter-assay coefficients of variation (CVs) for aldosterone were 7.9 and $9.6 \%$ respectively. The intra- and inter-assay CVs for PRA were 5.4 and 9.1\% respectively. Patients were left in a recumbent position for $1 \mathrm{~h}$ before supine samples were collected and for $2 \mathrm{~h}$ in an upright position before upright samples were collected. Plasma cortisol was measured using a specific RIA kit (INCSTAR; Sorin Biomedical) from blood samples collected at $0800 \mathrm{~h}$.

The sum of urinary corticosterone metabolites tetrahydro-corticosterone (THB), allo-tetrahydro-corticosterone (alloTHB) and 11-dehydro-tetrahydrocorticosterone (THA) was used as an index of corticosterone generation rate. Procedures for the extraction, purification and quantitation of THB, alloTHB and THA have been described in detail elsewhere (21). Briefly, steroid metabolite conjugates were extracted from aliquots of $24 \mathrm{~h}$ urine collections and hydrolysed using a preparation of $\beta$-glucuronidase. Methyloxime trimethylsilyl ether derivatives were synthesized and the resulting mixture analysed by gas chromatography-mass spectrometry.

\section{PCR amplification and genotyping of CYP11B2}

Genomic DNA was prepared from peripheral blood leucocytes with microspin columns (Qiamp blood kit; Qiagen, Valencia, CA, USA). Analysis of the D147E mutation was performed by first amplifying this region by PCR using gene-specific primers (sense: $5^{\prime}$-TGG GGC TGG ACC TTC CCG CAT-3'; antisense: $5^{\prime}$-TTC CAG AGC AGG TTC CTG GG-3'). The $50 \mu \mathrm{l}$ reaction was subjected to 35 cycles of $94{ }^{\circ} \mathrm{C}$ for $1 \mathrm{~min}, 65^{\circ} \mathrm{C}$ for $1 \mathrm{~min}$ and $72{ }^{\circ} \mathrm{C}$ for $2 \mathrm{~min}$ with an additional $5 \mathrm{~s}$ each cycle, followed by a final extension at $72{ }^{\circ} \mathrm{C}$ for $7 \mathrm{~min}$. This reaction allows the amplification of a $2.8 \mathrm{~kb}$ fragment that includes exons 1-3 of CYP11B2. The amplified DNA samples were subjected to electrophoresis in a $1 \%$ agarose gel and transferred to nylon membranes (GENE Screen Plus; DuPont-New England Nuclear, Ontario, Canada) that were subsequently hybridized with oligonucleotides that had been radioactively labelled with $\left[\gamma^{32}{ }^{32} \mathrm{P}\right] \mathrm{ATP}$ and T4 polynucleotide kinase. The membranes were incubated with the appropriate radiolabelled allele-specific oligonucleotide (D147: 5'-CCAGATGTGCTGTCGCC; E147: 5'-CCAGAAGTGCTGTCGCC-3') in a solution containing $0.9 \mathrm{~mol} /$ $1 \mathrm{NaCl}, 0.09 \mathrm{~mol} / \mathrm{l} \mathrm{Na}$ citrate, $1 \%$ SDS and $1 \times$ Denhardt's solution (1\% Ficoll, $1 \%$ polyvinylpyrrolidone and $1 \%$ BSA fraction $\mathrm{V}$ ) for $4 \mathrm{~h}$ at $42{ }^{\circ} \mathrm{C}$. The final stringent washes before autoradiography were conducted in $0.9 \mathrm{~mol} / \mathrm{l} \mathrm{NaCl}, 0.09 \mathrm{~mol} / \mathrm{l} \mathrm{Na}$ citrate and $0.5 \%$ SDS at $54{ }^{\circ} \mathrm{C}$. As a positive control we used a CYP11B2 cDNA carrying the mutation D147E 
introduced by PCR mutagenesis. Results were compared using Student's $t$-test.

\section{Results}

Clinical and hormonal parameters of the different subgroups of patients studied are summarized in Table 1.

The urinary excretion rates of $\mathrm{THB}$, alloTHB and THA were significantly higher $(P<0.01)$ in the group of patients with $\mathrm{EH}$ compared with the control group.

We did not find any allele carrying the E147 residue in the CYP11B2 gene in any of our samples of hypertensive patients and normal volunteers. All the PCR products transferred to the nylon membranes were hybridized with the end-labelled oligonucleotide specific for the D147 allele. In a sample of ten patients with IHA and ten with EH presenting with an increased corticosterone secretion, we also sequenced exon 3 of CYP11B2 as previously described (22), confirming the absence of the mutation D147E as shown by the hybridization studies (Fig. 1).

In all groups of patients we found a high frequency of conversion between the CYP11B1 and CYP11B2 genes, but never involving the sequence coding for amino acid residue $147(6,12)$.

\section{Discussion}

$11 \beta$-Hydroxylase and aldosterone synthase catalyse the terminal steps in cortisol and aldosterone biosynthesis in human adrenal cortex. Both enzymes are able to

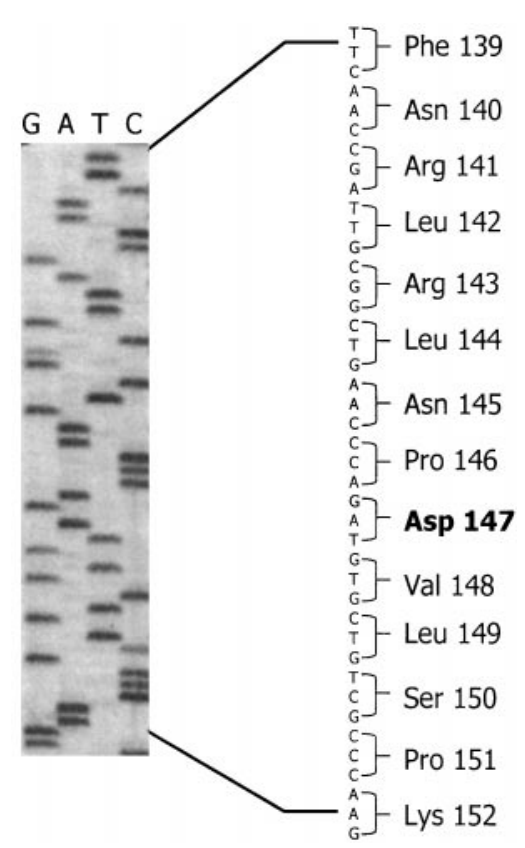

Figure 1 Sequence of exon 3 of CYP11B2 from a patient with PA. perform 11 $\beta$-hydroxylation of the substrate, but only aldosterone synthase is able to further catalyse 18hydroxylation and 18-oxidation of the substrate corticosterone. Single amino acids are responsible for the additional activities in position C18 displayed by aldosterone synthase: Gly288 confers the 18-hydroxylase activity to the enzyme and Ala320 confers 18oxidase activity $(5,6)$. Therefore, single amino acid substitutions can determine important changes in the enzyme activity.

It has been shown by in vitro studies that mutations in the human CYP11B2 gene corresponding to the mutations observed in the same gene in the Dahl SR strain of rat caused an increased production of corticosterone and aldosterone (16). However, such mutations have never been described in human hypertensive patients (our unpublished observations). A recent study by Fisher et al. (17) showed that the conservative substitution of Asp147 in CYP11B2 by the corresponding residue coded by CYP11B1 results in an enzyme which catalyses increased production of corticosterone and aldosterone. A gene conversion between the CYP11B1 and CYP11B2 genes could be responsible for this substitution in vivo. This kind of recombination is a frequent event between this type of highly homologous gene $(6,11,23,24)$. Gene conversions between $21 \alpha$-hydroxylase (CYP21A) and a highly homologous pseudogene carrying deleterious mutations (CYP21B) are responsible for a high percentage of $21 \alpha$-hydroxylase deficiencies (25).

Mutations of the type described in the work of Fisher et al. could have a relevance in human hypertension and in particular in patients with an increased production of corticosterone and aldosterone. It has previously been noted that plasma corticosterone concentration tends to be slightly raised in young adults with a familial predisposition to hypertension (26). Moreover, corticosterone production rate from isolated adrenocortical cells is higher in tissues from SHR rats, a model for $\mathrm{EH}$, than from WKY rats (27). Also, the hypertensive strain of the Milan rat has higher plasma corticosterone concentrations (28). Corticosterone displays $20 \%$ of the potency of cortisol and circulates at concentrations $1-2 \%$ of those of cortisol, but 20-40 times higher than aldosterone. In this respect, the contribution of an increased secretion of corticosterone would be expected to play a marginal role in hypertension. However, corticosterone binds $11 \beta$-hydroxysteroid dehydrogenase with greater affinity than cortisol (29); an impaired activity of the enzyme has been demonstrated in $\mathrm{EH}$ patients (21). For these reasons an increased secretion of corticosterone in $\mathrm{EH}$ patients could play a role in the pathogenesis of the disease.

Thus, one would expect to find the described mutation in patients with increased corticosterone secretion previously reported by Soro et al. (18) or in patients with PA. 
However, we did not find the D147E mutation in a large sample of patients with IHA, aldosterone-producing adenomas and in $\mathrm{EH}$ patients with an increased production of corticosterone.

This work demonstrates that if the D147E mutation exists it is very rare and so is not an important determinant in the increased steroid excretion seen in some subtypes of human hypertension.

\section{References}

1 Taymans SE, Pack S, Pak E, Torpy DJ, Zhuang Z \& Stratakis CA. Human CYP11B2 (aldosterone synthase) maps to chromosome 8q24.3. Journal of Clinical Endocrinology and Metabolism $1998 \mathbf{8 3}$ 1033-1036.

2 Mornet E, Dupont J, Vitek A \& White PC. Characterization of two genes encoding human steroid 11-beta-hydroxylase (P-450 $11 \beta$ ). Journal of Biological Chemistry 1989264 20961-20967.

3 Curnow KM, Tusie-Luna MT, Pascoe L, Natarajan R, Gu JL, Nadler JL et al. The product of CYP11B2 gene is required for aldosterone biosynthesis in the human adrenal cortex. Molecular Endocrinology 19915 1513-1522.

4 Pascoe L, Jeunemaitre X, Lebrethon MC, Curnow KM, GomezSanchez CE, Gasc JM et al. Glucocorticoid-suppressible hyperaldosteronism and adrenal tumors occurring in a single French pedigree. Journal of Clinical Investigation 199596 2236-2246.

5 Curnow KM, Mulatero P, Emeric-Blanchouin N, AupetitFaisant B, Corvol P \& Pascoe L. The amino acid substitutions Ser288Gly and Val320Ala convert the cortisol producing enzyme, CYP11B1, into an aldosterone producing enzyme. Nature Structural Biology 19974 32-35.

6 Mulatero P, Curnow KM, Aupetit-Faisant B, Foekling M, GomezSanchez C, Veglio F et al. Recombinant CYP11B genes encode enzymes which catalyse conversion of 11-deoxycortisol to cortisol, 18-hydroxycortisol and 18-oxocortisol. Journal of Clinical Endocrinology and Metabolism $1998 \mathbf{8 3} 3996-4001$.

7 Lifton RP, Dluhy RG, Powers M, Rich GM, Cook S, Ulick S et al. A chimaeric 11-beta-hydroxylase/aldosterone synthase gene causes glucocorticoid-remediable aldosteronism and human hypertension. Nature $1992355262-265$.

8 Pascoe L, Curnow KM, Slutsker L, Connell JM, Speiser PW, New MI et al. Glucocorticoid-suppressible hyperaldosteronism results from hybrid genes created by unequal crossovers between CYP11B1 and CYP11B2. PNAS $1992898327-8331$.

9 Torpy DJ, Gordon RD, Lin JP, Huggard PR, Taymans SE, Stowasser $\mathrm{M}$ et al. Familial hyperaldosteronism type II: description of a large kindred and exclusion of the aldosterone synthase (CYP11B2) gene. Journal of Clinical Endocrinology and Metabolism 199883 3214-3218.

10 Fallo F, Veglio F, Mulatero P, Sonino N, Pilon C, Barzon L et al. Genetic studies in familial aldosteronism not suppressible by dexamethasone. Journal of Endocrine Genetics 20001 159-164.

11 Brand E, Chatelain N, Mulatero P, Fery I, Curnow KM, Jeunemaitre X et al. Structural analysis and evaluation of the aldosterone synthase gene in hypertension. Hypertension 1998 32 198-204.

12 Mulatero P, Schiavone D, Fallo F, Rabbia F, Pilon C, Chiandussi L et al. CYP11B2 gene polymorphisms in idiopathic hyperaldosteronism. Hypertension $200035694-698$.

13 Cicila GT, Rapp JP, Wang J-M, St Lezin E, Ng SC \& Kurtz TW. Linkage of $11 \beta$-hydroxylase mutations with altered steroid biosynthesis and blood pressure in the Dahl rat. Nature Genetics 19933 346-353.

14 Matsukawa N, Nonaka Y, Higaki J, Nagano M, Mikami H, Ogihara $\mathrm{T}$ et al. Dahl's salt-resistant normotensive rat has mutations in cytochrome P450(11ß), but the salt-sensitive hypertensive rat does not. Journal of Biological Chemistry 1993 268 9117-9121.
15 Cover CM, Wang J-M, St Lezin E, Kurtz TW \& Mellon SH. Molecular variants in the P450c11AS gene as determinants of aldosterone synthase activity in the Dahl rat model of hypertension. Journal of Biological Chemistry $1995 \mathbf{2 7 0}$ 16555-16560.

16 Fardella CE, Rodriguez H, Hum DW, Mellon SH \& Miller WL. Artificial mutations in P450c11AS/aldosterone synthase can increase enzymatic activity: a model for low-renin hypertension. Journal of Clinical Endocrinology and Metabolism 199580 10401043.

17 Fisher A, Fraser R, Connell JMC \& Davies E. Amino acid residue 147 of human aldosterone synthase and 11-beta-hydroxylase plays a key role in 11-beta-hydroxylation. Journal of Clinical Endocrinology and Metabolism 200085 1261-1266.

18 Soro A, Ingram MC, Tonolo G, Glorioso N \& Fraser R. Mildly raised corticosterone excretion rates in patients with essential hypertension. Journal of Human Hypertension 19959 391-393.

19 Mulatero P, Veglio F, Pilon C, Rabbia F, Zocchi C, Limone P et al. Diagnosis of glucocorticoid-remediable aldosteronism in primary aldosteronism: aldosterone response to dexamethasone and long polymerase chain reaction for chimeric gene. Journal of Clinical Endocrinology and Metabolism $1998 \mathbf{8 3} 2573-2575$.

20 Veglio F, Rabbia F, Mengozzi G, Mulatero P, Zocchi C, Martini G et al. Assessment of a threshold value of the aldosterone/plasma renin activity ratio in the screening of primary aldosteronism. Internal Medicine 19997 1-8.

21 Soro A, Ingram MC, Tonolo G, Glorioso N \& Fraser R. Evidence of co-existing changes in $11 \beta$-hydroxysteroid dehydrogenase and $5 \beta$-reductase activity in subjects with untreated essential hypertension. Hypertension 199525 67-70.

22 Portrat-Doyen S, Tourniaire J, Richard O, Mulatero P, AupetitFaisant B, Curnow KM et al. Isolated aldosterone synthase deficiency caused by simultaneous E198D and V386A mutations in the CYP11B2 gene. Journal of Clinical Endocrinology and Metabolism $1998 \mathbf{8 3} 4156-4161$.

23 Pascoe L, Curnow KM, Slutsker L, Rosler A \& White PC. Mutations in the human CYP11B2 (aldosterone synthase) gene causing corticosterone methyloxidase II deficiency. PNAS $1992894996-5000$.

24 Fardella CE, Hum DW, Rodriguez H, Zhang G, Barry FL, Ilicki A et al. Gene conversion in the CYP11B2 gene encoding P450c11AS is associated with, but does not cause, the syndrome of corticosterone methyloxidase II deficiency. Journal of Clinical Endocrinology and Metabolism 199681 321-326.

25 Tusie-Luna MT \& White PC. Gene conversions and unequal crossovers between CYP21 (steroid 21-hydroxylase gene) and CYP21P involve different mechanisms. PNAS 19959210796 10800.

26 Watt GC, Harrap SB, Foy CJ, Holton DW, Edwards HV, Davidson HR et al. Abnormalities of glucocorticoid metabolism and the renin-angiotensin system: a four corner approach to the identification of genetic determinants of blood pressure. Journal of Hypertension 199210 473-482.

27 Kenyon CJ, Panarelli M, Holloway CD, Dunlop D, Morton JJ Connell JM et al. The role of glucocorticoid activity in the inheritance of hypertension in the rat: studies in man and the rat. Journal of Steroid Biochemistry and Molecular Biology 199345 $7-11$.

28 Stewart PM, Whorwood CB, Valentino R, Burt D, Shepperd MC \& Edwards CR. 11-Beta-hydroxysteroid dehydrogenase activity and gene expression in the hypertensive Bianchi-Milan rat. Journal of Hypertension 199311 349-354.

29 Stewart PM, Murry BA \& Mason JI. Human kidney $11 \beta$ hydroxysteroid-dehydrogenase is a high affinity nicotinamide adenine dinucleotide-dependent enzyme and differs from the cloned type I isoform. Journal of Clinical Endocrinology and Metabolism 199479 480-484.

Received 20 August 2000

Accepted 13 December 2000 